\title{
Blood Glucose and Serum Insulin Levels in Children with Cystic Fibrosis
}

\author{
A. D. MILNER \\ From The Hospital for Sick Children, London
}

Impaired glucose tolerance was shown to be present in a proportion of children with cystic fibrosis more than 30 years ago (Andersen, 1938), though symptomatic diabetes mellitus was not recognized as a complication until 1955 (Schwachman and Leubner, 1955).

This paper presents the results of blood glucose and serum insulin levels after oral and intravenous glucose, and after intravenous glucagon and tolbutamide, in a series of children with cystic fibrosis, including two with symptomatic diabetes mellitus. These investigations were done to discover which patients were at risk as regards diabetes mellitus. In addition, they provide further information on the mechanism of impaired glucose tolerance in cystic fibrosis.

\section{Subjects and Methods}

Of the 61 children investigated, 27 were in-patients at the time of the tests and 34 were out-patients. All had clinical features of cystic fibrosis and sweat sodium levels greater than $70 \mathrm{mEq} / \mathrm{l}$. All were on normal diets, with good carbohydrate intake, apart from one who had a disaccharide-free diet. The fat intake in 2 of the children was mainly medium-chain triglycerides. Control values for insulin levels after oral glucose loads were obtained from investigations carried out earlier by this laboratory on 22 in-patient children who were subsequently found to have no features which might be expected to affect glucose or insulin response.

Oral glucose tolerance test with insulin levels. The children were fasted for 12 hours before the test with the exception of those under 1 year who were fasted for 6 hours.

Capillary blood samples obtained by finger-prick were collected after an oral $20 \%$ glucose load. Further samples were then collected at 30-minute intervals for $2 \frac{1}{2}$ hours. Dosage was calculated from the formula of Poulton and Payne (Wilkinson, 1960).

Glucose and insulin levels after intravenous glucose load. After a 12-hour fast, venous samples

Received November 12, 1968. were collected before, and at $3,15,30,45,60$, and 75 minutes after an intravenous glucose load of $0.5 \mathrm{~g} . / \mathrm{kg}$. body weight, given as a $50 \%$ solution over 45 seconds (Crawford, 1938).

A scalp vein needle was left inserted in an antecubital vein for the duration of the test, and between sampling the needle was connected to a slow normal saline drip to maintain patency. The blood glucose results were plotted on semi-logarithmic graph paper, with the glucose levels in logarithmic scale in ordinate and the time as abscissa, providing a straight line relation. From this, the time taken for the blood sugar to return to $100 \mathrm{mg} . / 100 \mathrm{ml}$. blood was measured (Crawford, 1938). In addition, the coefficient of glucose assimilation, $\mathrm{K}$, a measure of tissue avidity for glucose, was calculated from the formula of Conard (1955).

Glucose and insulin levels after intravenous glucagon. The procedure described above was followed except that glucagon, $20 \mu \mathrm{g} . / \mathrm{kg}$. (Chiumello, del Guercio, and Bidone, 1968), was given intravenously over a period of 15 seconds instead of the glucose load.

Glucose and insulin levels after intravenous tolbutamide. The same procedure was adopted for this investigation, tolbutamide $25 \mathrm{mg}$. $/ \mathrm{kg}$. being given intravenously over 15 seconds (Chiumello et al., 1968).

Blood sugar estimations. Blood samples were collected into sodium fluoride and estimated by a modified method of Folin and Wu (Wilkinson, 1960). In addition, 77 samples were also estimated using a glucose oxidase method (Huggett and Nixon, 1957).

Serum insulin levels. Serum insulin levels were estimated by radioimmunoassay according to the method of Grant (1968), which is a modification of the double antibody method of Morgan and Lazarow (1963). All samples were in duplicate, and values over $40 \mu \mathrm{U} / \mathrm{ml}$. were repeated after double dilution, as the accuracy of this method falls over that level. Insulin estimations carried out on 6 different occasions on a control plasma gave a mean result of $36 \mu \mathrm{U} / \mathrm{ml}$. with a standard deviation of $\pm 2 \cdot 5 \mu \mathrm{U} / \mathrm{ml}$.

\section{Results}

Oral glucose tolerance test. According to 
TABLE I

Incidence of Glucose Tolerance Test Groups in Children with Cystic Fibrosis at Different Age-groups

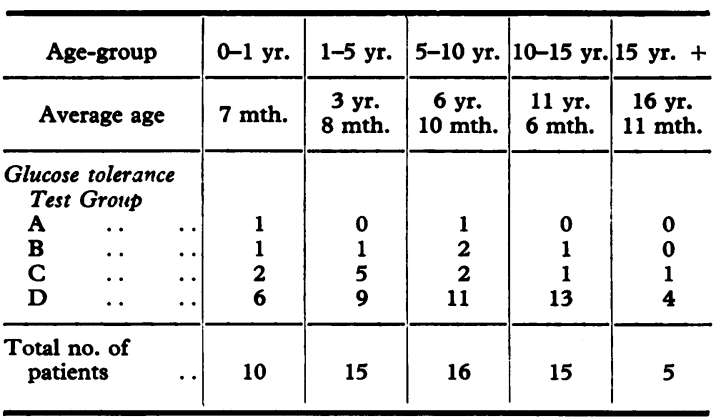

the results of the glucose tolerance tests, the patients were arranged into the following groups. (a) Symptomatic diabetes: Blood sugar rising above $190 \mathrm{mg}$. $/ 100 \mathrm{ml}$., with symptoms of diabetes, i.e. polyuria, polydipsia, etc.

(b) Chemical diabetes: Blood sugar rising above $190 \mathrm{mg} . / 100 \mathrm{ml}$., but no symptoms of diabetes.

(c) Impaired tolerance: Blood glucose not rising above $190 \mathrm{mg} . / 100 \mathrm{ml}$. but with blood glucose of over $120 \mathrm{mg}$. $/ 100 \mathrm{ml}$. at 2 hours.

(d) Normal glucose tolerance: Blood glucose not rising above $190 \mathrm{mg} . / 100 \mathrm{ml}$. and falling below $120 \mathrm{mg} . / 100 \mathrm{ml}$.

Of the 61 children, 18 were found to have abnormal glucose tolerance tests, of which 2 had symptomatic diabetes mellitus, 5 had chemical

\section{TABLE II}

Time taken for Blood Glucose to Fall to $100 \mathrm{mg}$./ $100 \mathrm{ml}$. blood after Intravenous Glucose Load

\begin{tabular}{|c|c|c|c|c|}
\hline Age-group & Case No. & $\begin{array}{l}\text { Time for Blood } \\
\text { Glucose to Fall to } \\
100 \mathrm{mg} . / 100 \mathrm{ml} \text {. } \\
\text { (min.) }\end{array}$ & K Value & $\begin{array}{l}\text { Glucose } \\
\text { Tolerance } \\
\text { Group }\end{array}$ \\
\hline \multirow[t]{2}{*}{$5-10 \mathrm{yr}$} & $\begin{array}{l}1 \\
2 \\
3 \\
4\end{array}$ & $\begin{array}{r}160 \\
64 \\
54 \\
51\end{array}$ & $\begin{array}{l}0 \cdot 66 \\
1 \cdot 61 \\
1 \cdot 5 \\
1 \cdot 73\end{array}$ & $\begin{array}{l}\text { A } \\
\text { B } \\
\text { D } \\
\text { D }\end{array}$ \\
\hline & Average* & 51 & $1 \cdot 61$ & \\
\hline \multirow[t]{2}{*}{$10-15 \mathrm{yr}$} & $\begin{array}{l}5 \\
6 \\
7 \\
8\end{array}$ & $\begin{array}{l}66 \\
64 \\
70 \\
51\end{array}$ & $\begin{array}{l}1 \cdot 42 \\
1 \cdot 38 \\
1 \cdot 26 \\
1 \cdot 98\end{array}$ & $\begin{array}{l}\text { C } \\
\text { D } \\
\text { D } \\
\text { D }\end{array}$ \\
\hline & Average & 63 & $1 \cdot 51$ & \\
\hline
\end{tabular}

* Average excludes Case 1 who had symptomatic diabetes.

The glucose assimilation constant $\mathrm{K}$, and the glucose tolerance test group in the 8 children studied are shown. The average values do not include Case 1 who had symptomatic diabetes.

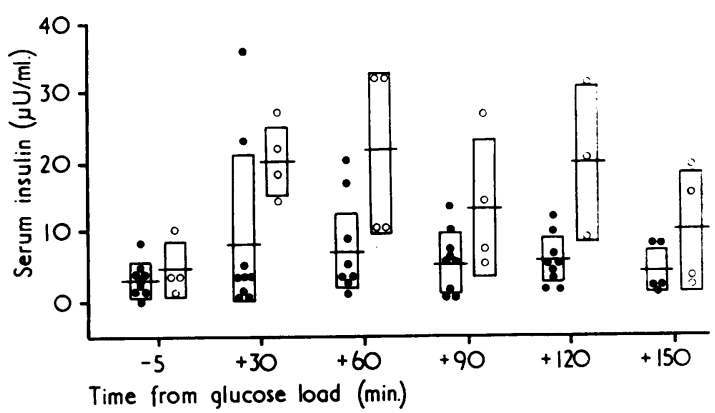

Fig. 1.-Serum insulin levels after oral glucose load in children aged 0-1 year. Mean values and $\pm S D$ are shown. $\bullet=$ children with cystic fibrosis; $\bigcirc=$ controls.

diabetes, and 11 had impaired tolerance. These abnormalities were more common in the younger children, as shown in Table $I$. No correlation could be found between impaired glucose tolerance and height or weight centiles, family history of diabetes mellitus, or severity of chest $x$-ray changes.

Insulin levels after oral glucose load. (Fig. 1-5). The serum insulin response to oral glucose load in the 61 children with cystic fibrosis was low relative to the controls in all age-groups studied, but showed the normal tendency to increase with age.

Blood glucose levels after intravenous glucose load. This investigation was carried out on 8 children including 1 (Case 1), who had symptomatic diabetes mellitus, and 1 (Case 2), with chemical diabetes mellitus. The blood glucose took an abnormally long time to return to $100 \mathrm{mg}$. $/ 100 \mathrm{ml}$. after an intravenous glucose load, and the co-

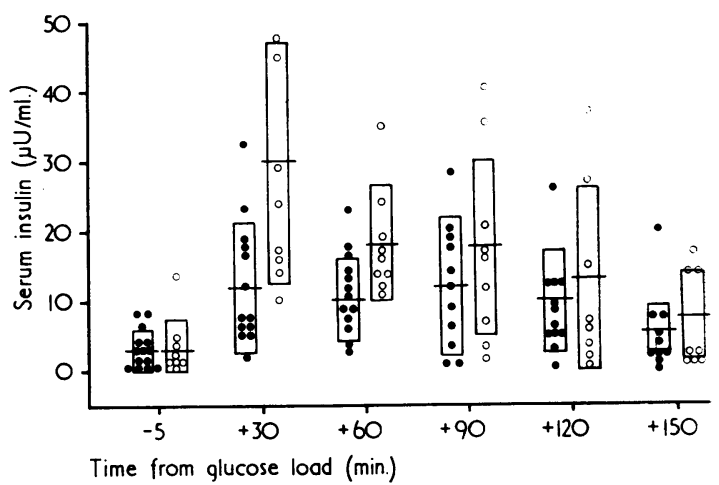

Fig. 2.-Serum insulin levels after a glucose load in children aged 1-5 years. Mean values and $t S D$ are shown. $\bullet=$ children with cystic fibrosis; $O=$ controls. 


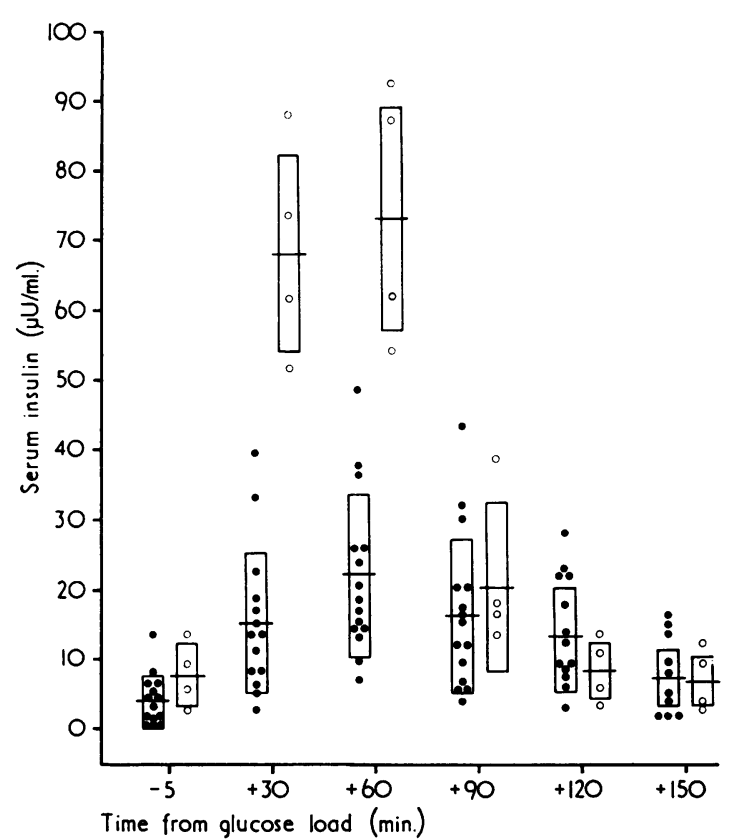

FIG. 3.-Serum insulin levels after oral glucose load in children aged 5-10 years. Mean values and $\pm S D$ are shown. $\quad=$ children with cystic fibrosis; $O=$ controls.

efficient of glucose assimilation $\mathrm{K}$ was low in all children studied. The results are shown in detail in Table II.

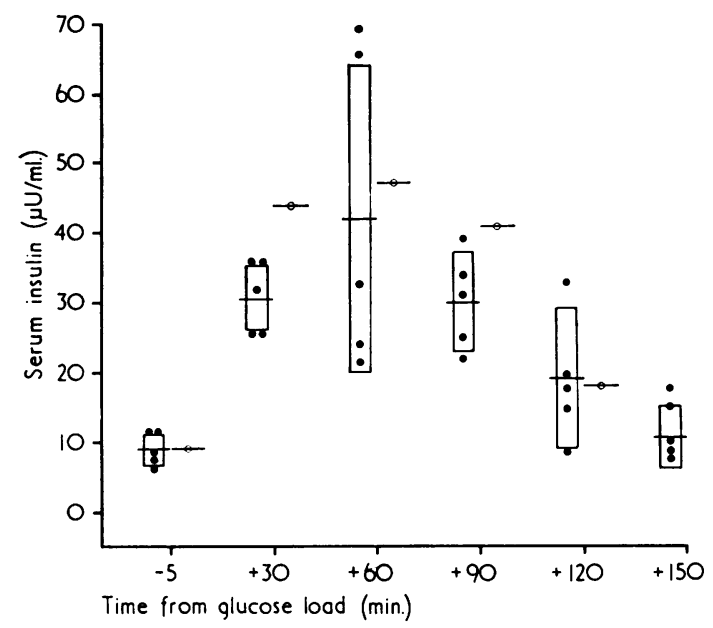

FIG. 5.- Serum insulin levels after oral glucose load in adolescents aged 15 years and over. Mean values and $\pm S D$ are shown for the children with cystic fibrosis. Only mean values are available for adult controls (Welborn et al., 1966). $\bullet=$ adolescents with cystic fibrosis; $\mathrm{O}=$ adult controls.

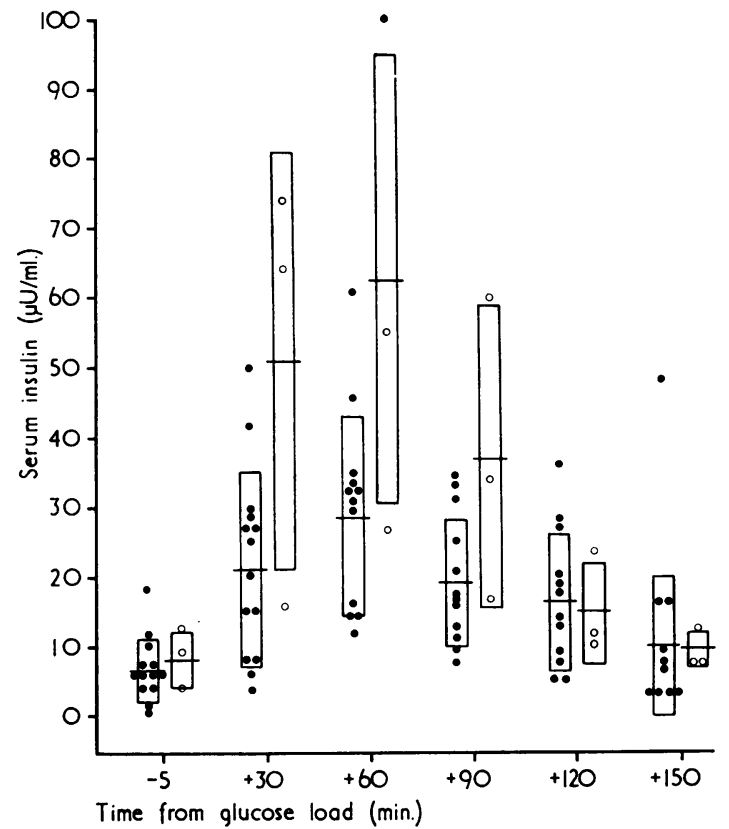

FIG. 4.-Serum insulin levels after oral glucose load in children aged 10-15 years. Mean values and $\pm S D$ are shown. $\bullet=$ children with cystic fibrosis; $\bigcirc=$ controls.

Insulin levels after intravenous glucose load. The mean maximum insulin response was higher to intravenous than to oral glucose loads in the 8 children with cystic fibrosis investigated. The results are shown in Fig. 6.

Glucose levels after intravenous tolbutamide. The blood glucose fell to $85 \%, 70 \%$, and $66 \%$ of the fasting level in 3 children with cystic fibrosis. These children had a glucose tolerance test of (d), (c), and (b) types, respectively.

Insulin response to intravenous tolbutamide and intravenous glucagon. The insulin response to intravenous glucagon was measured in 4 patients, including the 3 children who were given intravenous tolbutamide. The maximum responses to glucagon and tolbutamide range from 17 to $30 \mu \mathrm{U} / \mathrm{ml}$. and are shown in Table III.

Estimation of blood glucose using glucose oxidase. Results were on average $15 \mathrm{mg} . / 100 \mathrm{ml}$. lower than those obtained by the Folin and Wu method.

\section{Discussion}

In 1938 Andersen reported on 3 children with cystic fibrosis who had abnormal glucose tolerance 


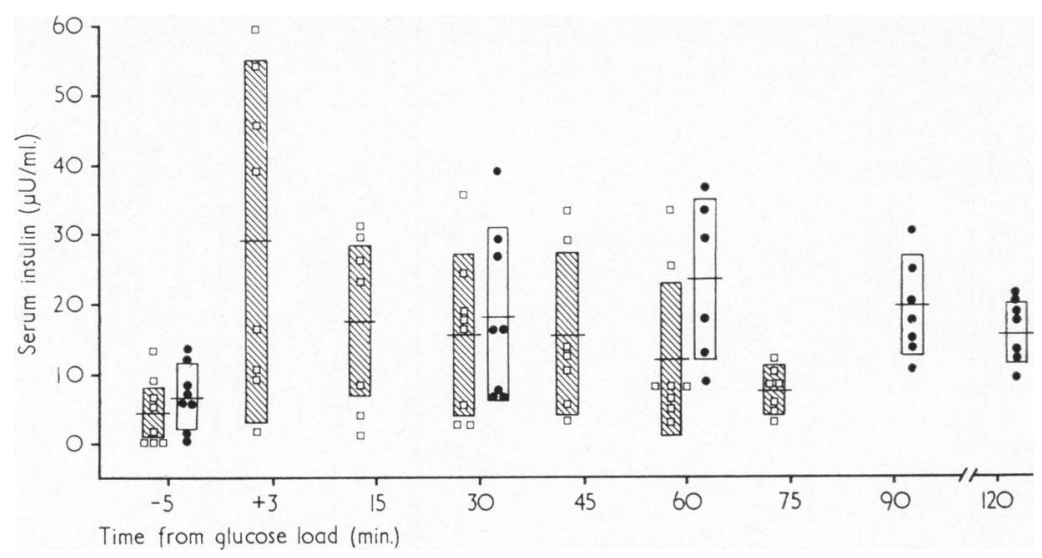

FIG. 6.-Serum insulin levels after oral and intravenous glucose loads in children with cystic fibrosis. Mean values and $\pm S D$ are shown. $\square$ and shaded $S D$ rectangles are results after intravenous glucose load; $\bullet$ and open rectangles are results after oral glucose load.

tests. Similarly, 3 out of 23 glucose tolerance tests carried out by Lowe, May, and Reed (1949) on a group of these children showed high peak values. The association of symptomatic diabetes mellitus and cystic fibrosis was first reported by Schwachman and Leubner (1955). In 1962, Rosan, Schwachman, and Kulczycki found 10 children with diabetes mellitus, in a group of 1300 children with cystic fibrosis attending the Boston Children's Hospital.

The British Diabetic Association survey on 45,500 schoolchildren in the Northampton area revealed an incidence of diabetes of $1 / 1200$ in children between the the ages of 5 and 16 years (Beardmore and Reid, 1966). This suggests that cystic fibrosis carries 10 times the normal risk for diabetes. However, 5 out of 30 glucose tolerance tests carried out by Rosan et al. (1962) on cystic fibrotic children, with no clinical evidence of diabetes, were in the diabetic range.

Of the 105 children currently attending the cystic fibrosis clinic at The Hospital for Sick Children, 2 had been found to have symptomatic

\section{TABLE III}

Maximum Insulin Level After Intravenous Glucagon and Tolbutamide

\begin{tabular}{c|c|c}
\hline $\begin{array}{c}\text { Case No. and Glucose } \\
\text { Tolerance Test Group }\end{array}$ & $\begin{array}{c}\text { Max. Insulin Level } \\
\text { after Glucagon } \\
(\mu \mathrm{U} / \mathrm{ml} .)\end{array}$ & $\begin{array}{c}\text { Max. Insulin I.evel } \\
\text { after Toltutamide } \\
(\mu \mathrm{U} / \mathrm{ml} .)\end{array}$ \\
\hline 6D & $26 \cdot 5$ & 30 \\
2B & $29 \cdot 5$ & $22 \cdot 5$ \\
5C & 17 & 30 \\
8D & 28.5 & - \\
\hline
\end{tabular}

diabetes mellitus. One (Case 9), who presented with meconium ileus aged 2 days, was first discovered to have diabetes when aged 6 months, having lost $10 \%$ of his body weight in 24 hours due to polyuria. $\mathrm{He}$ is believed to be the youngest child with cystic fibrosis reported to have developed this complication and is now well controlled on 3 units of insulin daily. The other child (Case 1) was found to have diabetes when aged 8 years, and has been well controlled on tolbutamide, 250 mg., t.d.s., for the past 9 months.

The results of the oral glucose tolerance tests show that there are other children, 16 out of the remaining 59, who have varying degrees of impaired glucose tolerance. This tendency is present in all age-groups but appears to be less frequent in the older children. However, no correlation could be found between this abnormality and any of the clinical features examined.

The insulin response to oral glucose was poor at all ages. This may in part be associated with the small stature of these children, as Grant found low levels in 9 abnormally small children (Grant, 1968). The values were particularly low in the 2 children with diabetes, $5 \mu \mathrm{U} / \mathrm{ml}$. in Case 9 and $8 \mu \mathrm{U} / \mathrm{ml}$. in Case 1, but similar levels were found in children with glucose tolerance levels which were within the normal range. Of the 16 children with impaired glucose tolerance, 8 had insulin levels above the average for their age-group. These findings conflict with those of Handwerger et al. (1968) who found a correlation between the severity of the glucose intolerance and the poverty of insulin response.

None of the intravenous glucose tolerance 
tests performed were within the normal range, as described by Crawford (1938), none returning to $100 \mathrm{mg} . / 100 \mathrm{ml}$. within 45 minutes of the administration of the glucose. The average time (excluding the diabetic child, Case 1) was 61 minutes.

Values obtained for the glucose assimilation constant $\mathrm{K}$ were also probably abnormal, being 1.61 for those under 10 years and 1.51 for those over 10 years. Control figures obtained by Loeb (1966) of $2 \cdot 7$ and $2 \cdot 3$, respectively, are not strictly comparable, as he gave $0.66 \mathrm{~g}$. glucose/ $\mathrm{kg}$., as against $0.5 \mathrm{~g}$. glucose given in this series.

The intravenous tolbutamide tolerance test gave a poor response in 1 out of 3 children, i.e. a fall to $85 \%$ of the fasting level. Rosan et al. (1961) found a similar response in one-third of children with cystic fibrosis.

The insulin responses to intravenous glucose, glucagon, and tolbutamide were more rapid than to oral glucose, but no significant difference could be detected in the insulin levels produced by these three stimuli. Though there was considerable overlap, the average insulin response to intravenous glucose was higher than that to oral glucose. This requires further elucidation but is in contradiction to the findings in normal adults who have a greater insulin response to oral than to intravenous glucose; this is thought to be due to a glucagon-like substance released from the liver or intestines (McIntyre, Holdsworth, and Turner, 1965).

These findings, which agree with those of Handwerger et al. (1968), are also found in patients with hepatic cirrhosis (Megyesi, Samols, and Marks, 1967), and it is hoped that further work will be carried out to assess liver function in these children.

These findings suggest that in cystic fibrosis there is a dual defect in insulin secretion: (1) defective release of insulin from the islet cells of the pancreas in response to hyperglycaemia; (2) defective release of a glucagon-like substance from the alimentary system.

It is not at present known whether the children found to have abnormal glucose tolerance tests are more liable to progress to symptomatic diabetes mellitus, but it is hoped that careful follow-up of these children will provide this information in the future.

\section{Summary}

The results of glucose and insulin levels after oral glucose and intravenous glucose, glucagon, and tolbutamide in 61 children with cystic fibrosis are presented. The results suggest that the increased incidence of impaired glucose tolerance found in them is due to a defect in the release of a glucagon-like substance from the alimentary system, in addition to defective islet cell function.

I wish to thank Dr. Barbara E. Clayton and Dr. A. P. Norman for their advice and encouragement, and Mrs. D. Jackson and the members of the Chemical Pathology Department at The Hospital for Sick Children, for their technical help; and Dr. Winifred F. Young of the Queen Elizabeth Hospital for Children, Hackney, and Dr. J. C. Batten of the Brompton Hospital, for permission to investigate children under their care.

Financial support was provided by the Joint Research Board of The Hospital for Sick Children and Institute of Child Health, and the Cystic Fibrosis Research Foundation Trust.

\section{REFERENCES}

Andersen, D. H. (1938). Cystic fibrosis of the pancreas and its relationship to celiac disease. Amer. F. Dis. Child., 56, 344.

Beardmore, M., and Reid, J. J. A. (1966). Diabetic children. Brit. med. F., 2, 1383.

Chiumello, G., del Guercio, M. J., and Bidone, G. (1968). Effects of glucagon and tolbutamide on plasma insulin levels in children with ketoacidosis. Diabetes, 17, 133.

Conard, V. (1955). Mesure de l'assimulation du glucose: bases théoriques et applications cliniques. Acta gastro-ent. Belg., $18,655$.

Crawford, T. (1938). A standard intravenous glucose tolerance test. Arch. Dis. Childh., 13, 69.

Grant, D. B. (1968). Insulin immunoassay in childhood. M.D. Thesis submitted to the Cambridge University Bcard.

Handwerger, S., Roth, J., Gorden, P., and di Sant'Agnese, P. A. (1968). Unusual insulin secretion characteristic of cystic fibrosis of the pancreas. (Abstract.) Pediat. Res., 2, 295.

Huggett, A. St. G., and Nixon, D. A. (1957). Use of glucose oxidase, peroxidase and $\mathrm{O}$-dianisidine in determination of blood and urinary glucose. Lancet, $2,368$.

Loeb, H. (1966). Variations in glucose tolerance during infancy and childhood. $\mathcal{F}$. Pediat., 68, 237.

Lowe, C. U., May, C. D., and Reed, S. C. (1949). Fibrosis of the pancreas in infants and children. Amer. F. Dis. Child., 78, 349.

McIntyre, N., Holdsworth, C. D., and Turner, D. S. (1965) Intestinal factors in the control of insulin secretion. $\mathcal{f}$. clin. Endocr., 25, 1317.

Megyesi, C., Samols, E., and Marks, V. (1967). Glucose tolerance and diabetes in chronic liver disease. Lancet, 2, 1051.

Morgan, C. R., and Lazarow, A. (1963). Immunoassay of insulin; two antibody system. Diabetes, $12,115$.

Rosan, R. C., Schwachman, H., and Kulczycki, L. L. (1962). Diabetes mellitus and cystic fibrosis of the pancreas. Laboratory and clinical observations. Amer. F. Dis. Child., 104, 625. - and Nieland, M. (1961). An investigation of diabetes mellitus in patients with cystic fibrosis. ibid., 102, 576.

Schwachman, H., and Leubner, H. (1955). Mucoviscoidosis. Advanc. Pediat., 7, 249.

Welborn, T. A., Rubenstein, A. H., Haslam, R., and Fraser, R. (1966) Normal insulin response to glucose. Lancet, 1, 280.

Wilkinson, R. H. (1960). Chemical Micromethods in Clinical Medicine, p. 67. Thomas, Springfield, Illinois; Blackwell, Oxford.

Correspondence to Dr. A. D. Milner, The Hospital for Sick Children, Great Ormond St., London W.C.1. 